\title{
Análise do atendimento ao Código Florestal e a regularização ambiental por unidades de bacias hidrográficas
}

\author{
Analysis of compliance with the Forest Code and environmental regularization \\ by hydrographic basin units
}

\author{
Gustavo Antomar Batista Gontijo', Luiz Antônio Coimbra Borges ${ }^{\mathrm{II}}$, \\ Sarita Soraia de Alcântara Laudares ${ }^{\mathrm{III}}$, Vanessa Cabral Costa de Barros ${ }^{\mathrm{IV}}$
}

\section{Resumo}

Após a sanção do Novo Código Florestal (CF), Lei no 12.651/2012, um dos maiores desafios, ainda a ser implementado, consiste em sanar conflitos de usos das propriedades rurais para regularizá-las e mantêlas sustentáveis. Estudos que apresentem diagnósticos sobre intervenções antrópicas, em desacordo com a legislação, tornam-se de suma importância para o desenvolvimento de ações preventivas e corretivas. Assim, objetivou-se com o presente estudo mapear, quantificar e caracterizar as áreas localizadas na Sub-bacia GD2 Vertentes do Rio Grande, no Estado de Minas Gerais, Brasil, a fim de avaliar o cumprimento da legislação vigente e indicar quais áreas devem ser recompostas ou compensadas, como meio de auxiliar o poder público quando da adoção de medidas mitigadoras e conservacionistas. Utilizou-se a divisão da região de análise em ottobacias com o intuito de criar áreas básicas para analisar, individualmente, o atendimento ao Código Florestal. Foram mapeadas 5 classes de ocupação do solo: Vegetação Nativa (20,75\%), Reflorestamentos $(4,29 \%)$, Massa d'água $(0,4 \%)$, Área Urbana (1,35\%) e Área Antropogênica (73,19\%). Os resultados apontaram que a área estudada encontra-se em acordo com a legislação, visto que existe vegetação nativa suficiente para compensação de Reserva Legal de todos os imóveis. No entanto, apenas 36,15\% dos 30 metros de Área de Preservação Permanente de cursos d'água estão cobertos com vegetação nativa, demonstrando que existem áreas passíveis de regularização pelo Programa de Regularização Ambiental, que poderão compor ainda mais o superavit de vegetação dentro da sub-bacia. A análise das 22 ottobacias mostrou as regiões que contribuem com o total de vegetação nativa da sub-bacia, indicando as áreas prioritárias para recuperação e as áreas com maior potencial para o incentivo da aplicação de Cotas de Reservas Ambientais. De forma geral, esta proposta contribuirá para amenizar os impactos gerados pela Lei 12.651/12 quanto à redução das áreas protegidas.

Palavras-chave: Legislação florestal; Reserva legal; Áreas de preservação permanentes; Adequação ambiental

\begin{abstract}
Following the enactment of the New Forest Code (CF), Law no. 12.651/2012, one of the greatest challenges, still to be implemented, is to address conflicts of use of rural properties in order to regularize and maintain them. Studies that present diagnoses on anthropic interventions, in disagreement with legislation, are of paramount importance for the development of preventive and corrective actions. Thus, the objective of this study was to map, quantify and characterize the areas located in the Sub Basin GD2 'Vertentes of Rio Grande', in the state of Minas Gerais, Brazil, in order to evaluate the compliance with the current legislation and indicate which areas should be recomposed or compensated, as a means to assist the public power when adopting mitigating and conservationist measures. The division of the analysis region into ottobacias was used to create basic areas to individually analyze the compliance with the Forest Code. Five classes of soil occupation were mapped: Native Vegetation (20.75\%), Reforestation (4.29\%), Water mass (0.4\%), Urban Area (1.35\%) and Anthropogenic Area, 19\%). The results showed that the studied area is in agreement with the legislation, since there is enough native vegetation to compensate Legal Reserve of all the properties. However, only $36.15 \%$ of the 30 meters of Permanent Preservation Area of watercourses are covered with native vegetation, demonstrating that there are

\footnotetext{
Engenheiro Florestal, Me., Doutorando em Engenharia Florestal, Departamento de Ciências Florestais, Universidade Federal de Lavras, Caixa Postal 3037, CEP 37200-000, Lavras (MG), Brasil. gontijo.florestal@gmail.com (ORCID: 0000-0001-6414-0369)

Engenheiro Florestal, Dr., Professor do Departamento de Ciências Florestais, Universidade Federal de Lavras, Caixa Postal 3037, CEP 7200-000, Lavras (MG), Brasil. luis.borges@dcf.ufla.br (ORCID: 0000-0003-0344-5008) Caixa Postal 3060, CEP 37200-000, Lavras (MG), Brasil. saritalaudares@gmail.com (ORCID: 0000-0003-4792-6663) Postal 3037, CEP 37200-000, Lavras (MG), Brasil. vanessacabralcb@gmail.com (ORCID: 0000-0002-0003-4599)
}

III Ciências Biológicas, Drª.., Analista de Capacitação Pleno, Fundação de Desenvolvimento Científico e Cultural, Universidade Federal de Lavras,

IV Engenheira Florestal, Ma., Doutoranda em Engenharia Florestal, Departamento de Ciências Florestais Universidade Federal de Lavras, Caixa
\end{abstract}


areas that can be regularized by the Environmental Regularization Program, which may further compound the "surplus" of within the Sub Basin. The analysis of the 22 ottobacias showed the regions that contribute with the total native vegetation of the Sub Basin, indicating the priority areas for recovery and the areas with greater potential for the incentive of the application of Quotas of Environmental Reserves. In general, this proposal will contribute to mitigate the impacts generated by Law 12.651/12 on the reduction of protected areas.

Keywords: Forestry legislation; Legal reserve; Permanent preservation areas; Environmental adaptation

\section{Introdução}

A inadequada gestão dos recursos naturais, com consequente demanda por expansão e supressão da vegetação nativa, aliada à contínua busca pela produtividade e à oportunidade de produção em áreas protegidas resultaram no grande problema das propriedades irregulares: o passivo ambiental. Como afirmaram Borges e Rezende (2011), apesar da obrigação legal de proteção das Áreas de Preservação Permanente (APP) e conservação das Reservas Legais (RLs), desde 1965, pela Lei no 4.771, para os produtores rurais, a manutenção dessas áreas não compensava, quando comparada ao custo de oportunidade de uso das mesmas.

Com vistas a regularizar os passivos ambientais foi sancionado a Lei de Proteção da Vegetação Nativa, no 12.651/2012, também conhecida como Novo Código Florestal. Ao tempo que a nova tutela jurídica manteve a obrigação legal de preservação e conservação dessas áreas, todos aqueles que as ocuparam ao revés da legislação, até 22 de julho de 2008, receberam a anistia de seus passivos e, agora, deverão conservar e/ou recuperar parte da vegetação nativa em extensão variável, conforme o tamanho da propriedade e a sua localização geográfica.

De acordo com o Art. 61-A, para as APP úmidas - ao longo dos rios ou qualquer curso d'água; ao redor de lagoas ou reservatórios, naturais ou artificiais; em nascentes ainda que intermitentes; e em veredas - foram estabelecidas metragens mínimas a serem recompostas, enquanto que, para as áreas de uso restrito (aquelas com inclinação entre 25a 45ํ) e para as APP de relevo, tais como topos de morros, encostas, tabuleiros ou chapadas, nenhuma metragem mínima a ser reconstituída foi exigida. Entende-se que nesses locais será permitida a continuação das atividades, desde que não haja novas supressões e que sejam mantidas técnicas de baixo impacto ambiental. Quanto às Reservas Legais, além de permitirem o cômputo do seu percentual em APP e aprovarem a compensação fora da microbacia a qual a propriedade pertence, os pequenos proprietários (aqueles com até 4 Módulos Fiscais (MF) e que atendam ao disposto no Art.3ํㅡㄹ da Lei da Política Nacional da Agricultura Familiar e Empreendimentos Familiares Rurais, n ${ }^{-11.326 / 2006) ~ e s t a r a ̃ o ~ d i s p e n s a d o s ~ d e ~ s u a ~ r e p o s i c ̧ a ̃ o . ~}$

Dentre as diversas discursões sobre o Código Florestal e sobre a importância da preservação ambiental desses espaços para manutenção da biodiversidade e preservação de recursos naturais (BRANCALION et al., 2016; SOARES-FILHO et al., 2014; SPAROVEK et al., 2011), Tambosi et al. (2015) destacaram as funções eco-hidrológicas das florestas nativas. Segundo os autores, a vegetação nativa situada em distintas posições do relevo, possuem diferentes funções eco-hidrológicas. Em topos de morros, por exemplo, a vegetação contribui para com a recarga de aquíferos; em encostas, para redução do escoamento superficial e contenção dos processos erosivos; em áreas ripárias, para proteção de corpos d'água; e em intervales, como elementos auxiliares em todas essas funções.

Ao considerar a importância desses espaços para equilíbrio e manutenção dos processos ecológicos, um dos maiores desafios ainda a ser implementado após a sanção do Novo Código Florestal consiste em sanar os conflitos de usos das propriedades rurais para regularizá-las e mantêlas sustentáveis. Estudos que apresentem diagnósticos sobre as intervenções antrópicas em desacordo com a legislação ambiental, isto é, que quantifiquem e avaliem o conflito de uso do solo, tornam-se de suma importância para o desenvolvimento de ações preventivas e corretivas.

Para a realização desses estudos, a tendência tem se concentrado na seleção de bacias hidrográficas como unidade de planejamento ambiental. Segundo Costa, Souza e Silva (2016), a amostragem por meio da seleção de bacias tem sido contemplada por várias ciências que enfocam não somente as questões relacionadas aos recursos hídricos, mas também, todos elementos físicos e antrópicos que as caracterizam. Piroli et al. (2002), salientam que a seleção de bacias hidrográficas para realização de estudos relativos ao ordenamento do solo, remetem-se à sua caracterização físico-espacial, sobretudo, topográficas com regiões altas, onde, geralmente, localizam-se as nascentes dos seus tributários (riachos e córregos), áreas de encostas e, por último, áreas de baixadas, em que normalmente observam-se as consequências de manejos inadequados aplicados nas áreas de maiores altitudes.

Depreende-se, portanto, que o êxito de políticas ambientais e de desenvolvimento rural, tem estreita relação com o planejamento, ordenamento e monitoramento ambiental, que por sua vez, demandam-se de estudos com informações espaciais fundamentados cientificamente. Dessa forma, objetivou-se com o presente trabalho, mapear, quantificar e caracterizar as áreas localizadas na Sub- 
bacia GD2 Vertentes do Rio Grande, no Estado de Minas Gerais, Brasil, a fim de avaliar o cumprimento da legislação vigente - com destaques para os riscos advindos de suas flexibilizações - e indicar quais áreas devem ser recompostas ou compensadas, como meio de auxiliar o poder público quando da adoção de medidas mitigadoras e conservacionistas para estes ambientes.

\section{Material e método}

\section{Área de estudo}

A Sub-bacia GD2 (Vertentes do Rio Grande) faz parte da Bacia do Rio Grande, tem uma área total de $10.513 \mathrm{Km}^{2}$, está inserida na mesorregião do Campo das Vertentes e apresenta uma área de drenagem de $10.513 \mathrm{~km}^{2}$. A região abrange um total de 29 sedes municipais, com população estimada de 522.135 habitantes.

Localizado entre as coordenadas Norte 7723439,3962; Sul 7607097,1464; Leste 647037,1116; Oeste 460157,6357 , os principais cursos d'água da sub-bacia concernem no próprio Rio Grande, no Rio das Mortes, no Rio dos Peixes, no Rio Jacaré e no Rio Cervo.

O clima regional na Sub-bacia GD2 pode ser definido pela Classificação de Köppen entre os tipos climáticos $\mathrm{Cw}$, que correspondem a verões brandos e clima úmido, com pluviosidade média anual de 1.400 $\mathrm{mm}$ a $1.550 \mathrm{~mm}$, em estação seca e curta, com temperaturas médias de $28^{\circ} \mathrm{C}$ no verão e $12^{\circ} \mathrm{C}$ no inverno e média anual em torno de $18,5^{\circ} \mathrm{C}$.

A Figura 1 apresenta a localização da Sub-bacia no Estado de Minas Gerais.

Figura 1 - Sub-bacia Hidrográfica GD2.

Figure 1 - GD2 Subwatershed.

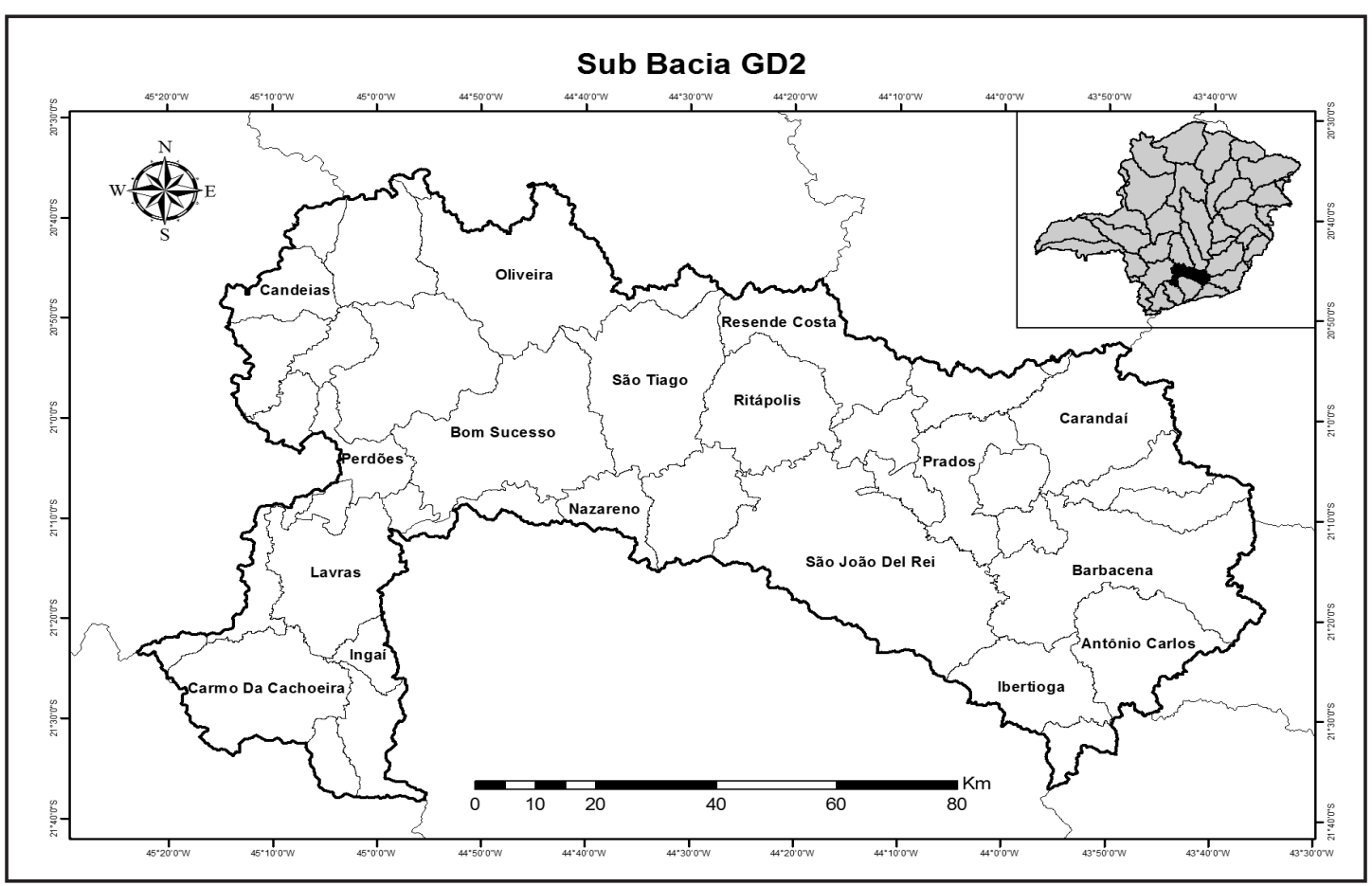

Fonte: Autores (2018)

\section{Ottobacias hidrográficas}

Com o intuito de criar áreas básicas para analisar, individualmente, o atendimento ao Código Florestal, foi utilizado o método de codificação de bacias hidrográficas proposto por Pfafstetter (1989). Devido aos fatores ambientais similares dentro de cada região, a utilização de Bacias Hidrográficas 
como unidades de gestão ambiental, é amplamente utilizada, como observado por Rodriguez, Silva e Leal (2011), Rodriguez (2008) e Botelho e Silva (2007). Além de ser uma divisão natural, a ottocodificação também é amplamente utilizada em virtude da "economia" de dígitos na nomenclatura comparando com outros métodos de divisão de bacias hidrográficas e também pela fácil interpretação do nome.

Além disso, o sistema de codificação e classificação de bacias desenvolvido por Otto Pfafstetter (1989) foi adotado oficialmente no Brasil pelo Conselho Nacional de Recursos Hídricos- CNRH, a partir da resolução n⿳0 30, de 11 de dezembro de 2002.

Para subdivisão da bacia GD2 foi utilizada a codificação de 6ª ordem, subdividindo a área de estudo inicial em 22 ottobacias.

\section{Processamento de imagens de satélite para obtenção de áreas de remanescente nativo}

Foram utilizados produtos do satélite Landsat-8 sensor Operational Land Imager (OLI) devido à média resolução espacial (30 x 30 metros), resolução temporal (16 dias) e, também, pela gratuidade da aquisição dos dados pelo Serviço Geológico dos Estados Unidos (USGS). Para o recobrimento da área de estudo, foram necessárias três cenas do satélite com as órbitas-pontos representadas por 217-75, 218-74 e 218-75 e datadas de 14 de maio, 05 de maio e 08 de julho de 2013, respectivamente. A seleção das imagens foi baseada na qualidade do produto e na ausência de nuvens sob a área de estudo nas datas de passagem.

Para cada imagem, foi realizada a segmentação. Trata-se de um processo realizado antes da classificação, com o objetivo de dividir a imagem em regiões homogêneas. O método consiste em separar os atributos espectrais da imagem em regiões similares, ou seja, unificar regiões de mesma classe de uso do solo.

Após a segmentação da imagem, foram coletadas as amostras de treinamento para suprir o algoritmo classificador Support Vector Machines (SVM) com parâmetros capazes de diferenciar o remanescente de vegetação, de outros alvos encontrados nas imagens de satélite.

A partir de coleta de verdades de campo (amostras), distribuídas aleatoriamente, foi realizada a mensuração da exatidão da classificação a partir dos valores da matriz de confusão, mediante estimativa KAPPA. Este é um dos principais índices para avaliar a assertividade do mapa temático com a realidade em campo, sendo o resultado variável de 0 a 1 . Quanto mais próximo de 1 , melhor a qualidade da informação gerada.

\section{Análise ambiental em conformidade com a Lei Federal nº12.651/2012}

Para avaliação da conformidade da sub-bacia com a legislação, observaram-se Áreas de Preservação Permanente cobertas por remanescentes nativos. A seguîr são apresentadas as classes de APP geradas e analisadas neste estudo

\section{APP em topos de morro e montanhas}

De acordo também com o Código Florestal (Lei 12.651/2012), identificam-se APPs: "no topo de morros, montes, montanhas e serras, com altura mínima de 100 (cem) metros e inclinação média maior que $25^{\circ}$, as áreas delimitadas conforme a curva de nível correspondente a $2 / 3$ (dois terços) da altura mínima da elevação sempre em relação à base, sendo esta definida pelo plano horizontal determinado por planície ou espelho d'água adjacente ou, nos relevos ondulados, pela cota do ponto de sela mais próximo da elevação" (BRASIL, 2012).

Para identificação destas áreas protegidas, foi utilizada a metodologia proposta por Oliveira e Fernandes Filho (2013), em que, por meio de processamentos de dados do Shuttle Radar Topography Mission (SRTM) de 30 metros, foi possível identificar as áreas de acordo com os parâmetros descritos na legislação.

\section{APP em zonas ciliares}

A área em torno dos cursos d'agua naturais, perenes e intermitentes, é variável, dependendo da largura do rio, como explicita a Tabela 1 a seguir. 
Tabela 1 - Largura de APP que deve ser preservada pela largura do rio.

Table 1 - The APP width that must be preserved in accordance with the width of the river.

\begin{tabular}{lc}
\hline \multicolumn{1}{c}{ Largura do Rio $(\mathbf{m})$} & Largura da APP $(\mathbf{m})$ \\
\hline Até $\mathbf{1 0}$ & $0-30$ \\
$\mathbf{1 0}-\mathbf{5 0}$ & 50 \\
$\mathbf{5 0}-\mathbf{2 0 0}$ & 100 \\
$\mathbf{2 0 0}-\mathbf{6 0 0}$ & 200 \\
Superior a $\mathbf{6 0 0}$ & 500 \\
\hline
\end{tabular}

Fonte: Autores (2018)

Sendo assim, foram vetorizados todos os cursos d'água, na área de estudo, e identificadas as larguras dos cursos d'água em toda a rede hidrográfica. Por conseguinte, a partir da borda da calha do leito regular, foram delineadas as larguras das APP correspondentes.

\section{Resultados e discussão}

No presente estudo, cinco classes de ocupação e cobertura do solo foram mapeadas, sendo elas: Vegetação Nativa, Reflorestamentos, Massa D’água, Área Urbana e Área Antropogênica (Figura 2).

Figura 2 - Mapeamento da cobertura do solo na Sub-bacia GD2.

Figure 2 - Land cover mapping in sub GD2 Basin.

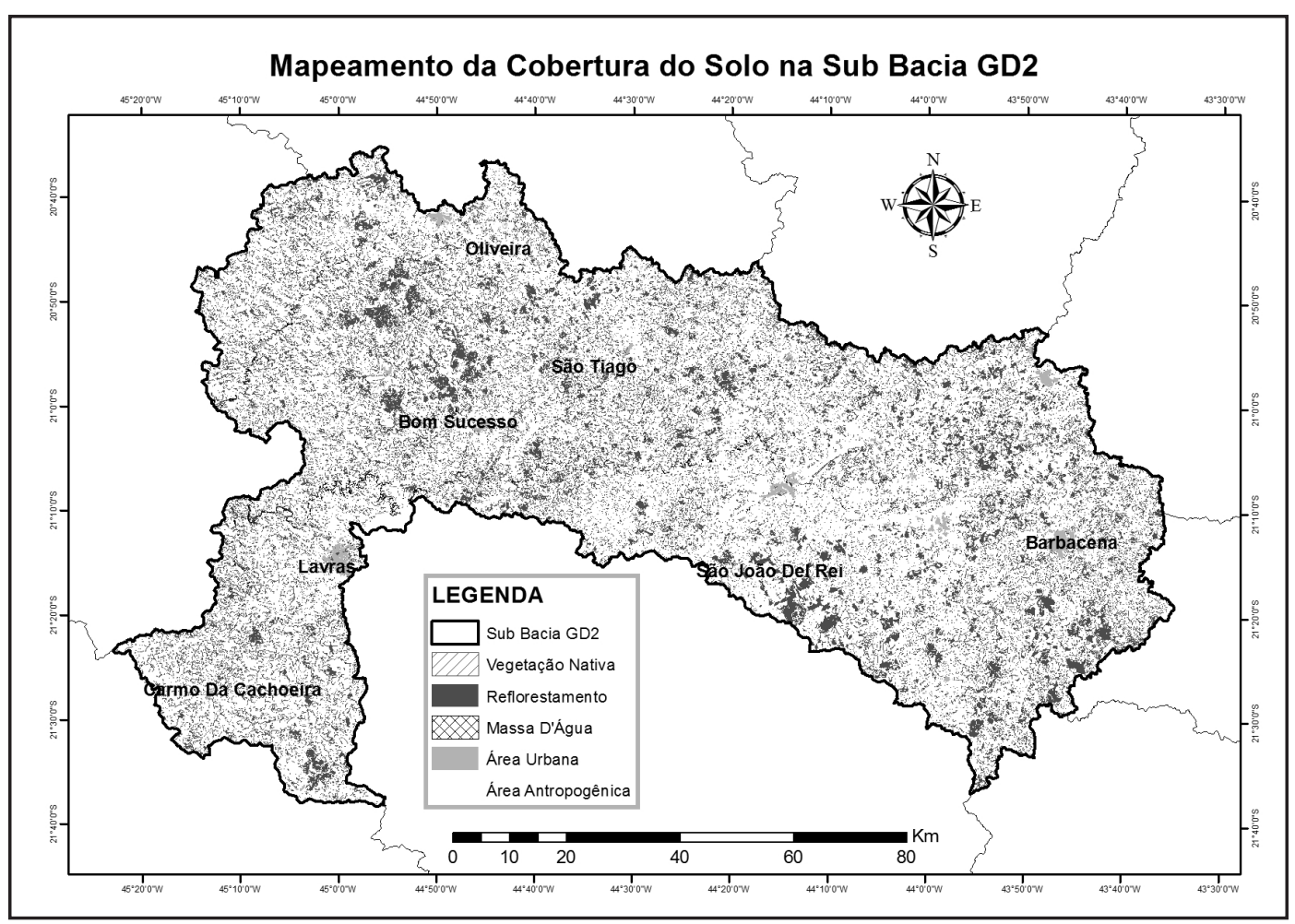

Fonte: Autores (2018) 
O índice Kappa, estimado para verificar a acurácia da imagem classificada, foi de 0,92, valor considerado excelente para a classificação de uso do solo, segundo os intervalos predefinidos por Landis e Koch (1977).

Com relação à cobertura do solo (Tabela 2), da área total da sub-bacia, 1.051.320,58 ha, 769.497,77 ha encontram-se ocupados por culturas anuais e por pastagens para alimentação de gado de corte e de leite, aqui denominadas "Áreas Antropogênicas"; 14.257,77 ha destinam-se às "Áreas Urbanas"; 45.145,72 ha destinam-se às áreas de reflorestamento; e 218.187,02 ha ainda dispõem de vegetação nativa.

Tabela 2 - Áreas de cada classe mapeada.

Table 2 - Area of each mapped class.

\begin{tabular}{lcc}
\hline \multicolumn{1}{c}{ Classes } & Área (hectare) & \% \\
\hline Vegetação Nativa & 218187,02 & 20,75 \\
Reflorestamento & 45145,72 & 4,29 \\
Massa D’água & 4232,34 & 0,40 \\
Área Urbana & 14257,72 & 1,35 \\
Área Antropogênica & 769497,77 & 73,19 \\
\hline Total & 1051320,58 & 100 \\
\hline
\end{tabular}

Fonte: Autores (2018)

Nota-se que a Sub-bacia Vertentes do Rio Grande, como um todo, está em conformidade com as Leis Federal no 12.651/2012 e Estadual de Minas Gerais no 20.922/2013, Arts. 12 e 25, respectivamente, os quais afirmam que todo imóvel rural deve manter uma área com cobertura de vegetação nativa, a título de RL, com um percentual mínimo de $20 \%$ para o estado. Este resultado revela que, mesmo que existam propriedades irregulares quanto ao cumprimento mínimo da Reserva Legal, ou seja, propriedades maiores do que 4 Módulos Fiscais que não detenham os 20\% de vegetação nativa exigida por lei, a sub-bacia em que se encontram, atende, como um todo, ao arcabouço jurídico ambiental. Esse percentual de vegetação nativa poderá ser ainda maior, visto que as APP que possuem usos conflitantes, com a legislação em vigor, deverão ser recompostas ainda que não seja realizada em sua totalidade - conforme as flexibilizações decorrentes do atual Código Florestal.

Em virtude da presença de vegetação nativa nessa sub-bacia, será possível aplicar duas alternativas para regularização das Reservas Legais: o cômputo e a compensação ambiental. Conforme o Art. 15, os proprietários ou possuidores de imóveis que dispuserem de vegetação nativa, nas APP, em percentuais iguais ou superiores ao percentual mínimo exigido para RL (20\% no caso de Minas Gerais), poderá utilizá-los para computar o deficit no seu próprio imóvel. Já a compensação serve para aqueles que desejarem regularizar seu passivo fora do seu imóvel. Os proprietários ou possuidores que optarem por esta alternativa poderão compensar seu deficit de vegetação nativa em outra área equivalente em importância ecológica e em extensão, desde que no mesmo bioma e, preferencialmente na mesma microbacia (BRASIL, 2012).

Salienta-se que estas flexibilizações poderão contribuir para a existência da fragmentação em determinadas microbacias. Em contrapartida, a regularização ambiental por sub-bacia poderá constituir em uma boa estratégia para mitigar problemas de fragmentação florestal. Os proprietários que decidirem por compensar suas RL poderão priorizar as áreas dentro da própria sub-bacia, e aqueles preferirem recompor uma nova área, poderão procurar por áreas ociosas e de maior importância ecológica dentro da mesma. Com isso, as RL poderão estar mais próximas, 
conectando as paisagens e cumprindo melhor o papel de conservação da fauna, flora e recursos hídricos.

\section{Identificação de APP na sub-bacia}

Dentre as alterações sancionadas pela Lei n⿳⺈ 12.651/2012, os maiores questionamentos pautaram-se sobre o Art. 61-A, o qual dispõe sobre a recomposição da vegetação nativa conforme o tamanho da propriedade rural. Também conhecida como "regra da escadinha", esta norma estabeleceu diferentes metragens para recomposição de APP úmidas, as quais poderão variar de 5 a 15 metros (a depender do tamanho do imóvel) e 20 a $100 \mathrm{~m}$ (conforme determinado pelo Programa de Regularização Ambiental).

$\mathrm{Na}$ prática, esta modificação impossibilitou a realização de pesquisas para quantificar APP com usos conflituosos, sem que se tenham informações sobre o tamanho dos imóveis da área de estudo. Contudo, para áreas que já possuem vegetação nativa, no entorno de cursos d'água de 10 metros, por exemplo, e que, portanto, possuem uma APP de 30 metros, independentemente do tamanho da propriedade deverão mantê-las protegidas a título de preservação permanente. Em vista disso, realizou-se, no presente estudo, uma análise dentre os 30 metros, em ambos os lados ao longo dos rios com a finalidade de identificar as APP com vegetação nativa remanescente, sem a possibilidade de quantificar a área que deverá ser recomposta.

A Tabela 3 apresenta a área de APP no entorno dos corpos d'água e a classe encontrada dentro do limite da APP. A coluna "Área (ha)" mostra o total da área mapeada da classe dentro da sub-bacia. A coluna "APP Rio (ha)" apresenta os valores de cada classe dentro da faixa de 30 metros ao longo dos rios. A coluna "porcentagem APP rio" apresenta a porcentagem da classe dentro da faixa de APP em relação à área total da sub-bacia. A coluna "APP \%" apresenta o valor de cada classe referente apenas à área total de APP ao longo dos rios.

Tabela 3 - Área de cada classe mapeada dentro do limite de APP ao longo dos rios.

Table 3 - Area of each class mapped within the APP limit along the rivers.

\begin{tabular}{lcccc}
\hline \multicolumn{1}{c}{ Classe } & Área $($ ha) & APP Rio $($ ha $)$ & Porcentagem APP Rio & APP \% \\
\hline Vegetação Nativa & 218187,02 & 50963,07 & 4,85 & 36,15 \\
Reflorestamento & 45145,72 & 3335,57 & 0,32 & 2,37 \\
Massa D’água & 4232,34 & 2155,32 & 0,21 & 1,53 \\
Área Urbana & 14257,72 & 1016,71 & 0,10 & 0,72 \\
Área Antropogênica & 769497,77 & 83504,95 & 7,94 & 59,23 \\
\hline Total & $1.051 .320,58$ & $140.975,62$ & 13,41 & 100 \\
\hline
\end{tabular}

Fonte: Autores (2018)

Observa-se, pela coluna "Porcentagem APP Rio", que 13,41\% da sub-bacia é composta por Área de Preservação Permanente de Rio (considerando a largura de 30 metros para todos os cursos d'água). Mesmo que a propriedade se classifique como familiar (BRASIL, 1993), caso exista vegetação nativa na faixa dos 30 metros de proteção, esta não poderá ser suprimida. A possibilidade de manter a faixa de proteção de acordo com a "regra da escadinha" (Tabela 4) será concedida, apenas, para fins de regularização ambiental. 


\section{Tabela 4 - Faixas de APP irregulares a serem recuperadas de acordo com o tamanho do imóvel.}

Table 4 - Zone of irregular APP to be retrieved according to the property size.

\begin{tabular}{|c|c|c|c|c|c|}
\hline & \multicolumn{5}{|c|}{ Módulos Fiscais } \\
\hline & Até 1 & $>1$ a 2 & $>2$ a 4 & $>4$ a 10 & $>10$ \\
\hline $\begin{array}{l}\text { Rios com largura } \\
\text { de: }\end{array}$ & $\begin{array}{l}\text { Qualquer } \\
\text { Largura }\end{array}$ & $\begin{array}{c}\text { Qualquer } \\
\text { Largura }\end{array}$ & $\begin{array}{l}\text { Qualquer } \\
\text { Largura }\end{array}$ & $10 \mathrm{~m}$ & Todos \\
\hline $\begin{array}{l}\text { Obrigação mínima } \\
\text { de Recompor a } \\
\text { APP: }\end{array}$ & $5 \mathrm{~m}$ & $8 \mathrm{~m}$ & $15 \mathrm{~m}$ & $20 \mathrm{~m}$ & $\begin{array}{c}\text { De } 30 \text { a } 100 \text { metros } \\
\text { em função da } \\
\text { largura do rio } \\
\text { (metade da largura } \\
\text { do rio) }\end{array}$ \\
\hline
\end{tabular}

Fonte: Autores (2018)

Em consideração às APP de rio, a coluna APP\% revela que $36,15 \%$ das áreas do entorno de cursos d'água, em uma largura de 30 metros, encontram-se cobertas com vegetação nativa. Ao se desconsiderar 1,53\% correspondente à classe "Massa d'água", o restante, isto é, $62,32 \%$, representam, em conjunto, as classes de "Reflorestamento", "Área Urbana" e "Área Antropogênica". Percebe-se que mais da metade das áreas destinadas à preservação permanente estão ocupadas com uso alternativo do solo, podendo comprometer importantes funções ecológicas, tais como: fornecimento de refúgio e alimentos para fauna terrestre e aquática; conexão entre ambientes para fomentar o fluxo gênico da flora e fauna; estabilização das margens dos rios, pela vegetação juntamente com toda a massa de raízes; manutenção do solo poroso capaz de absorver água das chuvas para alimentar os lençóis freáticos; e inúmeras outras funções.

Quanto às APP de morro, por meio do emprego do modelo digital de elevação SRTM de 90 metros de precisão, nenhuma área foi identificada, mesmo utilizando a interpolação de cotas para 30 metros. Ainda que o relevo apresente regiões com declividades acentuadas, infere-se que o "desaparecimento" destas áreas, relaciona-se às mudanças dos parâmetros de enquadramento dessas APP, advindas com o atual Código Florestal. Embora pareça uma mudança amena, alterar a declividade mínima de $17^{\circ}$ para $25^{\circ}$, adotar o ponto de sela como base de morros em relevos ondulados e impor uma altura mínima de 100 metros, em vez de 50 metros, para que os topos se enquadrassem como APP, restringiram e fizeram com que as áreas não fossem incluídas na categoria.

Em conformidade, Nery et al. (2013) verificaram redução de um percentual de 13,05\% das APP em topos de morro em comparação ao Código Florestal Brasileiro de 1965. Varjabedian e Mechi (2013) mostraram que, em pontos distintos no Brasil, a alteração de critérios constante no Inciso IX do Artigo $4^{\circ}$ da Lei Federal n. ${ }^{\circ}$ 12.651/12, em relação aos estabelecidos pela Lei Federal n. ${ }^{-}$4.771/1965 (BRASIL, 1965) e pela Resolução CONAMA n. ${ }^{\circ}$ 303/2002 (BRASIL, 1965; 2002), representa, na prática, o desaparecimento e/ou enorme redução da proteção conferida para as Áreas de Preservação Permanente de Topo de Morro, Montanhas e Serras. E a estimativa realizada por Soares-Filho et al. (2014) revela redução de, aproximadamente, $87 \%$ nas APP de topo de morro no conjunto territorial brasileiro.

É nítido que estas modificações demandam embasamentos científicos, e a Lei vigente não fornecerá a proteção necessária para as APP de topo de morro. Salienta-se que a vegetação nativa situada em diferentes posições do relevo, segundo Tambosi et al. (2015), possui diferentes funções eco-hidrológicas, como recarga de aquíferos, redução do escoamento superficial e contenção de processos erosivos nas encostas, além da proteção de corpos 
d'água. Perdas de vegetação nativa podem comprometer, conforme Brancalion et al. (2016), a manutenção dos serviços ambientais como proteção do solo, regulação climática, purificação da água e polinização de cultivos agrícolas, agravando problemas como deslizamento de encostas, inundações e secas.

\section{Análise da vegetação nativa por ottobacias}

Diversos estudos, relativos ao planejamento, controle ou gestão ambiental, utilizaram bacias hidrográficas como unidade amostral (CABRAL et al., 2011; SOARES, 2011; CUNHA et al., 2012; NASCIMENTO E FERNANDES; 2017). Sua precisa delimitação permite não somente a realização de estudos, como também o planejamento para adequada ocupação e uso pela sociedade (COSTA; SOUZA; SILVA, 2016).

A escolha por uma sub-bacia, como a GD2, se justifica por esta conter um comitê gestor que trata das situações ambientais em seu interior. Ressalta-se que, a fim de detalhar e localizar mais precisamente as regiões que contribuem satisfatoriamente, ou não, com vegetação nativa, foram codificadas 22 ottobacias de $6^{\mathbf{a}}$ ordem dentro da Sub-bacia GD2 (Figura 3).

Figura 3 - Ottobacias delimitadas dentro da Sub-bacia GD2.

Figure 3 - Ottobacias defined within the Sub-Basin GD2.

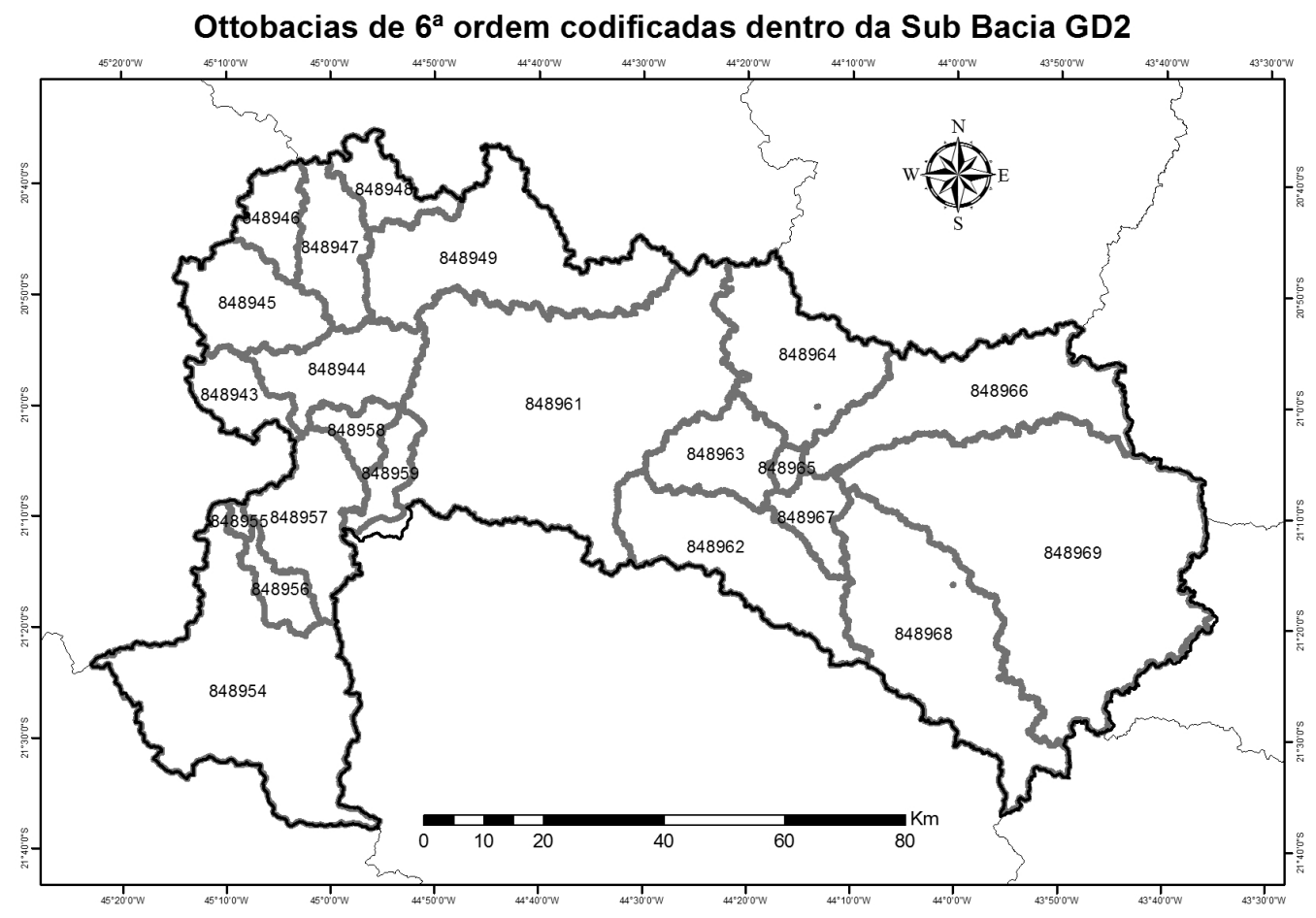

Fonte: Autores (2018)

Detalhadamente, a Tabela 5 apresenta a área de vegetação nativa mapeada dentro de cada ottobacia de $6^{a}$ ordem e a porcentagem em relação à área total da ottobacia. 


\section{Tabela 5 - Área das ottobacias de 6 ${ }^{\mathbf{a}}$ ordem e a área de vegetação nativa encontrada dentro de cada.}

Table 5 - Area of 6 th order Ottobacias and native vegetation area found within each.

\begin{tabular}{|c|c|c|c|}
\hline $\begin{array}{c}\text { Código } \\
\text { Ottobacia }\end{array}$ & $\begin{array}{c}\text { Área da Ottobacia } \\
(\text { ha })\end{array}$ & $\begin{array}{c}\text { Área de Vegetação } \\
\text { Nativa (ha) }\end{array}$ & $\begin{array}{c}\text { Porcentagem } \\
\text { de Vegetação } \\
\text { Nativa }\end{array}$ \\
\hline 848943 & $16.169,54$ & $3.739,36$ & 23,13 \\
\hline 848944 & $31.423,09$ & $8.383,51$ & 26,68 \\
\hline 848945 & $32.441,99$ & $7.048,26$ & 21,73 \\
\hline 848946 & $15.318,56$ & $3.756,23$ & 24,52 \\
\hline 848947 & $25.322,76$ & $6.263,37$ & 24,73 \\
\hline 848948 & $15.918,01$ & $2.829,57$ & 17,78 \\
\hline 848949 & $74.448,48$ & $15.105,78$ & 20,29 \\
\hline 848954 & $109.978,65$ & $24.805,13$ & 22,55 \\
\hline 848955 & $1.777,85$ & 537,44 & 30,23 \\
\hline 848956 & $10.484,11$ & $1.716,93$ & 16,38 \\
\hline 848957 & $35.477,88$ & $6.352,47$ & 17,91 \\
\hline 848958 & $9.700,82$ & $2.435,00$ & 25,10 \\
\hline 848959 & $11.271,27$ & $2.755,36$ & 24,45 \\
\hline 848961 & $173.351,21$ & $41.076,12$ & 23,70 \\
\hline 848962 & $56.228,42$ & $7.350,73$ & 13,07 \\
\hline 848963 & $26.628,29$ & $5.405,24$ & 20,30 \\
\hline 848964 & $51.413,73$ & $9.510,18$ & 18,50 \\
\hline 848965 & $3.375,21$ & 494,04 & 14,64 \\
\hline 848966 & $67.162,68$ & $11.172,76$ & 16,64 \\
\hline 848967 & $13.598,53$ & $1.011,45$ & 7,44 \\
\hline 848968 & $86.301,94$ & $14.391,20$ & 16,68 \\
\hline 848969 & $179.401,77$ & $40.726,08$ & 22,70 \\
\hline Total GD2 & $1.051 .320,58$ & $218.187,0185$ & 20,75 \\
\hline
\end{tabular}

Fonte: Autores (2018)

Observa-se que das 22 ottobacias, 13 encontram-se constituídas com mais de $20 \%$ de vegetação nativa e as nove restantes possuem em deficit de vegetação para o cumprimento da legislação florestal. Estas, portanto, devem ser prioritárias em programas de regularização ambiental, a fim de amenizar a degradação e a pressão sobre os recursos naturais. Como já alertado por Metzger (2010), é preciso cautela com a compensação ambiental. A possibilidade de compensar RL em qualquer área no mesmo bioma, ao invés de na mesma bacia hidrográfica, pode levar a uma concentração excessiva de RL em uma região, e desertos biológicos em outras áreas - formadas por amplas monoculturas em paisagens homogêneas. Por exemplo, em vez de se ter uma paisagem com $30 \%$ de vegetação nativa, pode ocorrer uma com $50 \%$ e outra com $10 \%$ de vegetação nativa. A paisagem de $10 \%$ será formada unicamente por fragmentos isolados, e 
poderá ser uma forte barreira para a movimentação de espécies em escala regional.

No geral, entende-se que a ottobacia está em legitimidade no quesito "atendimento limite de $20 \%$ de RL” conforme o Novo Código Florestal. No entanto, não quer dizer que todas as propriedades detêm o percentual mínimo de RL exigido por Lei. A subdivisão de uma bacia permitiu a identificação mais pontual, proporcionando a localização de áreas com maior deficit ou superavit de vegetação. Observa-se pela Tabela 5, que três ottobacias apresentam mais que $25 \%$ de vegetação nativa e, em contrapartida, três ottobacias apresentam menos que $15 \%$ de vegetação nativa. Sendo estas, localizadas em regiões em que a agricultura é mais desenvolvida em razão do relevo favorável para a atividade.

A regularização ambiental por sub-bacia é uma maneira de combater a pressão exercida sobre os recursos florestais naturais em todo o território e, também, uma maneira de auxiliar as decisões públicas quanto aos locais com maiores necessidades de investimentos para recuperação das APP e RL. Como revela o presente estudo, uma sub-bacia que detém quantidades de reservas inferiores ao necessário para cumprimento da Lei deverá ser prioritária para programas de recuperação ambiental. Os proprietários de terra pertencentes às sub-bacia, as quais detêm reservas em excedente de vegetação nativa, deverão ser orientados a compensar seus passivos, caso existentes, dentro da mesma sub-bacia. Este recurso da compensação, o qual a metodologia também incentiva, enfatiza a valoração dos recursos naturais como opção de renda para os proprietários rurais da região. O excedente de vegetação nativa de cada imóvel poderá ser comercializado por meio de Cotas de Reservas Ambientais, gerando fonte alternativa de renda e reduzindo a probabilidade de conversão de novas áreas para uso alternativo do solo.

O estudo mostra que é possível e aplicável a regularização ambiental dentro da subbacia, no entanto, fatores organizacionais e estruturais, dos órgãos estaduais responsáveis, serão de extrema importância para o sucesso, visto que são os principais atores de fiscalização nos processos de regularização. O Novo Código Florestal e as suas ferramentas - Cadastro Ambiental Rural (CAR), Cota de Reserva Ambiental (CRA) e Programa de Regularização Ambiental (PRA) - vieram, de certa forma, como facilitadores nos processos regulatórios. O Sistema Nacional de Cadastro Ambiental (SICAR) e os módulos incluídos para análise apoiarão os órgãos a fiscalizar e localizar passivos ambientais a serem regularizados. Resta ao órgão ambiental responsável atuar efetivamente sem transferir a responsabilidade, que lhe é incumbida, para terceiros e, principalmente, atuar sem onerar o proprietário no processo de fiscalização e regularização. Os avanços conquistados com a desburocratização do processo, desde a averbação da RL em cartório até os dias atuais com um sistema autodeclaratório gratuito, não podem ser barrados por uma fiscalização ineficiente nos Estados.

De forma geral, este estudo visa amenizar possíveis impactos ambientais negativos resultantes das atuais Leis no 12.651/2012 e no 20.922/2013, no tocante à redução das áreas protegidas e no tocante à possibilidade de compensação de reserva legais no mesmo bioma, uma vez que retrata e salienta a necessidade de proteção e recuperação da Sub-bacia GD2.

\section{Conclusões}

Infere-se que a ottobacia está em legitimidade no quesito "atendimento limite de $20 \%$ de RL” conforme o Novo Código Florestal. No entanto, não quer dizer que todas as propriedades detêm o percentual mínimo de RL exigido por lei. A análise da cobertura do solo em APP de rio mostrou que apenas $36,15 \%$ dos 30 metros mínimo exigido por lei estão cobertos com vegetação nativa. Porém, após as mudanças realizadas no novo Código Florestal, apenas imóveis acima de 10 módulos fiscais deverão recompor os 30 metros. Imóveis abaixo de $10 \mathrm{MF}$ seguem a "regra da escadinha”, em que propriedades de até 1 módulo fiscal deverão recompor até 5 metros da faixa lateral do rio. De qualquer maneira, as APP que forem recompostas, poderão fomentar a quantidade de reserva legal disponível em qualquer tamanho de imóvel e concomitantemente na sub-bacia. 
O resultado da análise de APP pode ter sido subestimado já que o sensor utilizado neste estudo tem 30 × 30 metros. Ou seja, alvos menores que 30 metros podem não ter sido representados nas imagens. Estudo complementares com utilização de sensores de melhor resolução serão necessários para comparar a precisão dos métodos.

Não foram encontradas APP de topo de morro na sub-bacia, fomentando a discussão de como algumas mudanças editadas na Lei no 12.651/2012 impôs prejuízos ambientais e, principalmente, nestas áreas protegidas que, além de estarem remotas, em várias situações excepcionais, nas quais as intervenções são possíveis de ocorrer, não há exigência de restauração quando suprimidas.

A análise "microescala" da vegetação nativa por ottobacia de 6" ordem pôde indicar dentro da sub-bacia, áreas em que o superavit de vegetação existe e onde há um deficit de vegetação nativa, mostrando regiões prioritárias para recuperação e, provavelmente, com proprietários rurais dispostos a utilizarem cotas de reserva ambiental de outras ottobacias para se regularizar.

\section{Referências}

BORGES, L. A. C.; REZENDE, J. L. P. Áreas protegidas no interior das propriedades rurais: a questão das APP e RL. Floresta e Ambiente, Seropédica, RJ, v. 18, n. 2, p. 210-222, jun. 2011.

BOTELHO, R. G. M.; DA SILVA, A. S. Bacia hidrográfica e qualidade ambiental. In: VITTE, A. C.; GUERRA, A. J. T. Reflexões sobre a geografia física no Brasil. 2. ed. Rio de Janeiro: Bertrand Brasil, p. 153-192, 2007.

BRANCALION, P. H. S. et al. A critical analysis of the Native Vegetation Protection Law of Brazil (2012): updates and ongoing initiatives. Natureza \& Conservação, Curitiba, PR, v. 14, p.1-15, abr. 2016.

BRASIL. Lei no 12.651, de 25 de maio de 2012. Instituiu o Novo Código Florestal Brasileiro. Brasília, DF, 2012. Disponível em: http://www.planalto.gov.br/ccivil_03/_Ato2011-2014/2012/Lei/ L12651.htm. Acesso em: 05 ago. 2013.

BRASIL. Lei no 4.771, de 15 de setembro de 1965. Instituiu o Código Florestal Brasileiro. Brasília, 1965. Disponível em: http://www.planalto.gov.br/ccivil_03/Leis/L4771.htm. Acesso em: 05 ago. 2013.

BRASIL. Lei no 8.629, de 25 de fevereiro de 1993. Dispõe sobre a regulamentação dos dispositivos constitucionais relativos à reforma agrária, previstos no Capítulo III, Título VII, da Constituição Federal. Brasília, DF, 1993. Disponível em: http://www.planalto.gov.br/ccivil_03/leis/18629.htm. Acesso em: 17 ago. 2014.

BRASIL. Medida Provisória no 2.166-67, de 24 de agosto de 2001 . Altera os arts. $1^{\circ}, 4^{\circ}, 14^{\circ}, 16^{\circ}$ e

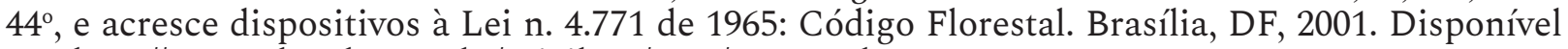
em: http://www.planalto.gov.br/ccivil_03/mpv/2166-67.htm. Acesso em: 05 ago. 2013.

BRASIL. Ministério do Meio Ambiente. Instrução Normativa no 2, de 5 de maio de 2014. Dispõe sobre os procedimentos para a integração, execução e compatibilização do Sistema de Cadastro Ambiental Rural-SI-CAR e define os procedimentos gerais do Cadastro Ambiental Rural-CAR. Diário Oficial da República Federativa do Brasil, Brasília, DF, n. 84, p. 59-62, 06 maio 2014. Seção 1.

BRASIL. Resolução Conama no 303, de 20 de março de 2002. Dispõe sobre parâmetros, definições e limites de Áreas de Preservação Permanente. Brasília, DF, 2002. Disponível em: http://www.mma. gov.br/port/conama/res/res02/res30302.html. Acesso em: 07 jul. 2013.

CABRAL, J. B. P. et al. Mapeamento da fragilidade ambiental da bacia hidrográfica do Rio Doce (GO), utilizando técnicas de geoprocessamento. GeoFocus, Madri, ES, v. 1, n. 11, p. 51-69, jan. 2011.

COSTA, F. R.; SOUZA, R. F.; SILVA, S. M. P. Análise comparativa de metodologias aplicadas à delimitação da bacia hidrográfica do Rio Doce-RN. Revista Sociedade \& Natureza, Uberlândia, 
MG, v. 28, n. 3, p. 429-442, set./dez. 2016.

CNRH - Conselho Nacional de Recursos Hídricos. Resolução no 30, de 11 de dezembro de 2002. Disponível em: http://www.cnrh.gov.br/divisao-hidrografica-nacional/73-resolucao-n-30-de-11-dedezembro-de-2002/file. Acesso em: 07 nov. 2018.

CUNHA, J. E. B. L. et al. Dinâmica da cobertura vegetal para a Bacia de São João do Rio do Peixe, PB, utilizando-se sensoriamento remoto. Revista Brasileira de Engenharia Agrícola e Ambiental, Campina Grande, PB, v. 16, n. 5, p. 539-548, fev. 2012.

LANDIS, J. R.; KOCH, G. G. The measurement of observer agreement for categorical data. Biometrics, Massachusetts, US, v. 33, n. 1, p. 159-174, 1977.

METZGER, J. O código florestal tem base científica? Conservação e Natureza, Curitiba, v. 8, n. 1, p. 92-99, 2010.

NASCIMENTO, T. V.; FERNANDES, L. L. Mapeamento do uso e ocupação do solo em uma pequena bacia hidrográfica da Amazônia. Ciência e Natura, Santa Maria, RS, v. 39, n. 1, p. 169-177, 2017.

NERY, C. V. M. et al. Aplicação do Novo Código Florestal na Avaliação das Áreas de Preservação Permanente em Topo de Morro na Sub-Bacia do Rio Canoas no Município de Montes Claros/MG. Revista Brasileira de Geografia Física, Recife, PE, v. 6, n. 6, p. 1673-1688, nov. 2013.

OLIVEIRA, G. C.; FERNANDES FILHO, E. I. Metodologia para delimitação de APPs em topos de morros segundo o novo Código Florestal brasileiro utilizando sistemas de informação geográfica. In: SIMPÓSIO BRASILEIRO DE SENSORIAMENTO REMOTO, 16., 2013, Foz do Iguaçu. Anais... Foz do Iguaçu: INPE, 2013. 1 CD-ROM.

PESSOA, M. C. P. Y. et al. Principais modelos matemáticos e simuladores utilizados para análise de impactos ambientais das atividades agrícolas. Jaguariúna: EMBRAPA/CNPMA, 1997. 83 p.

PFAFSTETTER, O. Classificação de bacias hidrográficas: metodologia de codificação. Unpublished Technical Report (in Portuguese). Departamento Nacional de Obras de Saneamento. Rio de Janeiro: DNOS, 1989. 19 p.

PIROLI, E. L. et al. Análise do uso da terra na microbacia do Arroio do Meio, Santa Maria, RS, por sistema de informações geográficas e imagem de satélite. Ciência Rural, Santa Maria, RS, v. 32, n. 3, p. 407-413, jun. 2002.

RODRIGUEZ, J. M. M. Planificación ambiental. La Habana: Ed. Félix Varela, 2008.

RODRIGUEZ, J. M. M.; SILVA, E. V.; LEAL, A. C. Planejamento ambiental de bacias hidrográficas desde a visão da geoecologia da paisagem. In. FIGUEIRÓ, A. S.; FOLETO, E (org.). Diálogos em Geografia Física, Santa Maria, RS,: Ed. da UFSM, 2011.

SOARES-FILHO, B. et al. Cracking Brazil's forest code. Science, Washington, US, v. 344, n. 6182, p. 363-364, abr. 2014.

SOARES, V. P. et al. Mapeamento de áreas de preservação permanentes e identificação dos conflitos legais de uso da terra na bacia hidrográfica do Ribeirão São Bartolomeu, MG. Revista Árvore, Viçosa, MG, v. 35, n. 3, p. 555-563, 2011.

SPAROVEK G et al. A revisão do Código Florestal Brasileiro. Novos estudos - CEBRAP, n. 89, p. 111-135.

TAMBOSI, L. R. et al. Funções eco-hidrológicas das florestas nativas e o Código Florestal. Estudos Avançados, São Paulo, SP, v. 29, n. 84, p. 151-162, ago. 2015.

VARJABEDIAN, R. MECHI, A. As APPS de Topo de Morro e a Lei no 12.651/12. 14º Congresso Brasileiro de Geologia de Engenharia e Ambiental, Anais... Rio de Janeiro - RJ, 2013. 